\section{Infracardiac Total Anomalous Pulmonary Venous Drainage}

Brit. med. J., 1968, 3, 35-36

Infracardiac total anomalous pulmonary venous drainage has been well documented in the literature but it is only in recent years that successful surgical correction has been reported. It is a rare congenital heart lesion comprising only $0.18 \%$ of total congenital cardiac defects (Nadas, 1963). In the past 10 months three infants with infracardiac total anomalous pulmonary venous drainage have been seen in this department. One survived, and this case is described in detail.

\section{Case History}

This infant was the fourth child of normal healthy parents. He was born at home, a normal delivery at full term. Birth weight was $7 \mathrm{lb} .2 \mathrm{oz}$. $(3,200 \mathrm{~g}$.). At the age of 6 days he was admitted to Luton and Dunstable Hospital with breathlessness and difficulty in feeding. He was in congestive heart failure, but failed to improve with digitalization and diuretics. He was transferred to Westminster Hospital at the age of 11 days.

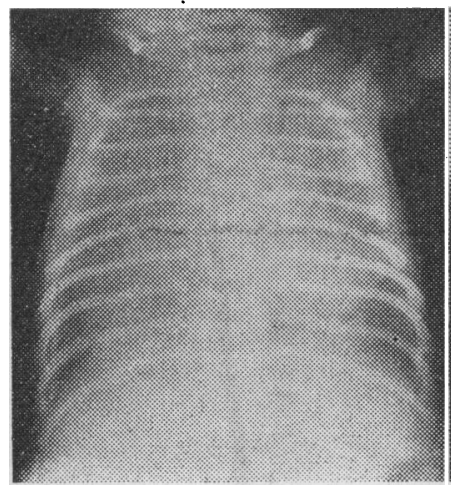

FIG. 1

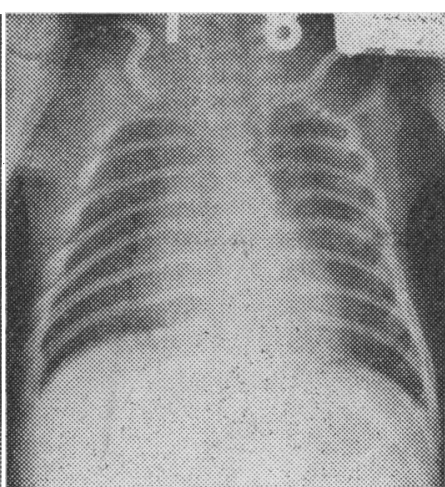

FIG. 2 FIG. 1.-Pre-operative chest $x$-ray picture. FIG. 2.-Chest $x$-ray film
two days postoperatively. when the oesophageal temperature had reached $31^{\circ}$ C. and the operation begun with the infant placed on a water blanket, so that further control of temperature was possible. Blood was replaced as lost throughout. At the time of circulatory arrest the nasopharyngeal temperature was $30^{\circ} \mathrm{C}$.

\section{Surgical Techrique}

The method was similar to that described by Cooley et al. (1966), except that surface cooling with inflow occlusion was used in place of cardiopulmonary bypass. The approach was through a median sternotomy. The heart was dislocated forwards and to the right by means of a stay stitch in the apex of the left ventricle. The heart was replaced every few minutes as the cardiac action deteriorated, allowing circulatory stabilization. The posterior pericardial reflection of the oblique sinus obscured the common pulmonary vein and its anomalous drainage. Needle aspiration confirmed the presence of pulmonary venous blood. The pericardium was incised, exposing the anomalous drainage and allowing a loose ligature to be placed around the inferior draining vessel near its diaphragmatic exit.

After inflow occlusion ventilation was discontinued and the heart was allowed to empty. Traction on the ligature around the inferior draining vessel occluded it. A vertical incision was preferred to the horizontal incision used by Cooley et al. (1966), for by continuing it into the draining vessel a longer anastomosis was obtained (Fig. 3). An oblique incision was made into the left atrium to conform with the obliquity of the dislocated heart and to prevent torsion of the anastomosis when the heart was replaced. Two stays joined each end of these two incisions and the anastomosis was completed by continuous over-and-over suture. Heparinized saline was injected into the cavity of the left atrium just before closure, to force out air. Ventilation was restarted. After closure the left ventricle was aspirated, but no air was present. The heart was replaced and the inflow tapes were released. The occlusion time was six minutes. After stabilization the loose ligature around the inferior draining vessel was tied. The pericardium was closed anteriorly with drainage of the oblique sinus.

Water at $37^{\circ} \mathrm{C}$. was run through the blanket to aid rewarming. After closure at a nasopharyngeal temperature of $35^{\circ} \mathrm{C}$., reversal of curarization was produced with neostigmine $0.2 \mathrm{mg}$. and atropine $0.1 \mathrm{mg}$.

On leaving the theatre the infant was awake, moving vigorously, and breathing satisfactorily. The circulation was stable and vaseconstriction gave way to vasodilatation on normal temperature being reached in the ward.

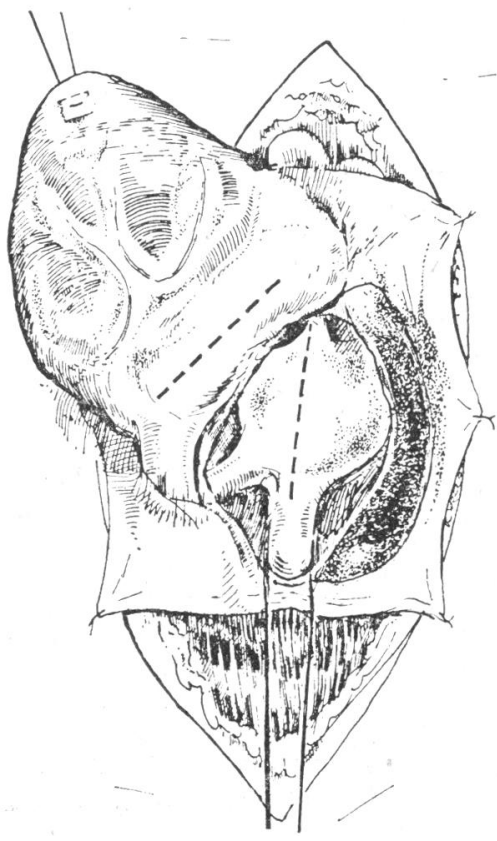

FIG. 3.-A median sternotomy exposes the heart. This has been displaced upwards and to the right by a stitch in its apex. The posterior reflection of pericardium of the oblique sinus has been opened. The common collecting chamber of the blood returning from the lungs is joined to the left atrium along the interrupted lines. A thread occludes the anomalous drainage during anastomosis and is later tied. and the infant ventilated with a Starling pump (tidal volume $40 \mathrm{ml}$., rate $28 / \mathrm{min}$.). A further two $0.5-\mathrm{mg}$. doses of tubocurarine were required later in the procedure. Surface cooling was begun, with use of crushed ice in polyethylene bags applied to the trunk and groins, monitoring pulse, blood pressure, electrocardiogram, and oesophageal and nasopharyngeal temperatures. Cooling was stopped 
The postoperative period was uneventful ; there was no evidence of cardiac failure. The infant was less dyspnoeic and within 12 hours was able to take oral feeds. There was a dramatic change in the $x$-ray appearance (Fig. 2).

The patient was discharged home 14 days after the operation.

At the age of 5 months the infant was readmitted. Apart from a respiratory infection he had been well and had thrived since discharge from hospital. He was on 50th percentile for weight. On examination he had a short soft systolic murmur maximal in the pulmonary area and an accentuated pulmonary second sound. The electrocardiogram was normal for his age, and the chest $x$-ray film showed moderate cardiac enlargement with prominence of the pulmonary artery shadow.

Cardiac catheterization and angiocardiography were performed. These showed a left-to-right shunt at atrial level (as shown by oxygen saturations and a left atrial injection). The shunt was calculated at $1: 1.25$. The pulmonary artery pressure was $33 / 15$. Pulmonary wedge pressure was $11 \mathrm{~mm} . \mathrm{Hg}$ and the left atrial pressure $5 \mathrm{~mm}$. $\mathrm{Hg}$. An Elema biplane selective angiocardiogram with tip of catheter in main pulmonary artery demonstrated a normal pulmonary arterial tree. Two large pulmonary veins drained into a small displaced left atrium.

Two earlier patients died within 24 hours of their admission. Both showed cyanosis and dyspnoea with the radiological appearance of a normal cardiac outline and gross pulmonary oedema, and a correct diagnosis was made. Surgery was attempted in the second case by using profound hypothermia (Drew et al., 1959), but the patient died during the immediate postoperative period. Total anomalous pulmonary venous drainage into the left hepatic vein was demonstrated in both cases at necropsy. A patent foramen ovale and a small left atrium were also present.

\section{Discussion}

The common pulmonary vein may fail to communicate with the pulmonary splanchnic plexus, and the umbilical and vitelline veins may persist, leading to anomalous pulmonary venous connexions (Edwards, 1953 ; Neill, 1956). In infracardiac drainage an anomalous vein descends through the diaphragm, draining into the portal or hepatic veins, so that both systemic and pulmonary blood enter the right heart. The infant survives because of a right-to-left shunt at atrial level, usually through a patent foramen ovale. However, the situation is critical because of the small size of the anomalous draining vessels which cause pulmonary venous obstruction. Death usually occurs within the first three months of life, unless there is surgical intervention (Guntheroth et al., 1958 ; Johnson et al., 1958 ; Burroughs and Edwards, 1960).

A clinical diagnosis is possible without submitting the patient to cardiac catheterization and angiocardiography. These infants present with dyspnoea and cyanosis, with or without a murmur, and with signs of pulmonary oedema. The electrocardiogram usually shows signs of right ventricular, and even atrial, hypertrophy. The radiological picture is diagnostic (Harris et al., 1960; Smith et al., 1961). A normal cardiac outline is associated with widespread reticular markings in both lung fields, suggesting pulmonary oedema. Obstructive lesions at left atrial level and beyond may present diagnostic difficulty, but the radiological findings and a right-sided electrocardiogram as found in this case are unusual at this age.

Three successful surgical corrections have been reported. Cooley and Balas (1962) and Cooley et al. (1966) describe the cases of three infants, one of whom died during the operative procedure and another of whom died two months postoperatively with stenosis at the site of the anastomosis. The third was corrected at the age of 7 weeks and was well four years later. Woodwark et al. (1963) reported a successful surgical correction at 6 weeks and the infant was well two years later.
Jegier et al. (1967) describe the case of the youngest infant, who had an anastomotic procedure at 6 days and who was well six months later. The surgery was similar in all cases. Total cardiopulmonary bypass was used and a direct anastomosis was performed between the left atrium and common pulmonary vein.

Correction of supracardiac and cardiac forms of total anomalous pulmonary venous drainage by means of surface-induced profound hypothermia with total circulatory arrest has been advocated as a safe and simple procedure in small infants. In four cases described by Dillard et al, (1967), temperature of 17.5 to $20.2^{\circ} \mathrm{C}$. were used with periods of up to 41 minutes' circulatory arrest.

We describe the above case for two reasons. Firstly, to demonstrate that a correct diagnosis can be made on clinical findings and on a straight $x$-ray examination of the chest, without submitting the ill infant to cardiac catheterization and angiocardiography, procedures which may be time-consuming and hazardaus to this type of patient. Secondly, it is the only case, to our knowledge, in which correction of infracardiac total anomalous pulmonary venous drainage has been successfully carried out with surface hypothermia and venous inflow occlusion rather than cardiopulmonary bypass, which is still a difficult procedure in the very small infant, and often requires assisted respiration in the postoperative period.

We wish to acknowledge the advice of Mr. Peter Jones, consultant thoracic surgeon, Westminster Hospital. We should also like to thank the photographic department of Westminster Hospital Medical School, and in particular their artist, Derek Watt.

Requests for reprints should be directed to P. A. Cullum, Department of Thoracic Surgery, Westminster Hospital, London S.W.1.

\author{
M. A. LlewelìiN, M.é.C.P., \\ Paediatric Cardiology Registrar. \\ P. A. Cullum, F.R.C.S., \\ Senior Thoracic Surgical Registrar. \\ J. B. Thomas, F.F.A. R.C.S., \\ Senior Anaesthetic Registrar. \\ I. M. ANDERSON, M.D., F.R.C.P., \\ Consultant Paediatrician. \\ Westminster Hospital, \\ London S.W.1.
}

\section{REFERENCES}

Burroughs, J. T., and Edwards, J. E. (1960). Amer. Heart 9. 59, 913. Cooley, D. A., and Balas, P. E. (1962). Surgery, 51, 798.

Cooley, D. A., Hallman, G. L., and Leachman, R. D. (1966). 9. thorac. cardiovasc. Surg., 51, 88.

Dillard, D. H., et al. (1967). Circulation, 35, Suppl. No. 1, 105.

Drew, C. E., and Anderson, I. M. (1959). Lancet, 1, 748.

Drew, C. E., Keen, G., and Benazon, D. B. (1959). Lancet, 1, 745.

Edwards, J. E. (1953). Proc. Mayo Clin., 28, 441.

Guntheroth, W. G., Nadas, A. S., and Gross, R. E. (1958). Circulation, 18, 117 .

Harris, G. B. C., Neuhauser, E. B. D., and Giedion, A. (1960). Amer. 9. Roentgenol., 84, 436.

Jegier, W., Charrette, E., and Dobell, A. R. C. (1967). Circulation, 35, 396.

Johnson, A. L., Wiglesworth, F. W., Dunbar, J. S., Siddoo, S., and Grajo, M. (1958). Circulation, 17, 340.

Nadas, A. S. (1963). Pediatric Cardiology, 2nd ed. London and Philadelphia.

Neill, C. A. (1956). Pediatrics, 18, 880.

Smith, B., Frye, T. R., and Newton, W. A. (1961). Amer. F. Dis. Child., $101,41$.

Woodwark, G. M., Vince, D. J., and Ashmore, P. G. (1963) \%. thorac. cardiovasc. Surg., 45, 662. 